\title{
Factors contributing to poor performance of student nurses in anatomy and physiology
}

X L Mhlongo, MCur (Nursing Education); T E Masango, PhD (Nursing Education)

Charles Johnson Memorial Nursing Campus, Nqutu, South Africa

Corresponding author: T E Masango (masante@unisa.ac.za)

Background. Student nurses in South Africa view anatomy and physiology (A\&P) as the most complex subject in the nursing curriculum. Objective. To describe the factors contributing toward inconsistent and fluctuating performance among student nurses doing A\&P as a subject. Methods. The study adopted a quantitative descriptive design. Census sampling was used to draw a sample size of 114 respondents. A structured self-administered questionnaire with close-ended questions was used to collect data from the six nursing campuses under study. Raw data were captured using Excel spreadsheets, and descriptive and inferential statistics were used to analyse data.

Results. The key findings were: (i) poor teaching strategies contributed to subject failure; (ii) lack of after-class sessions had an impact on failure; (iii) a shorter study period for examinations contributed to failure; and (iv) a language barrier also played an important role in students' failure in A\&P.

Conclusion. Student nurses struggle with and find A\&P in nursing programmes challenging and anxiety-provoking. Nurse educators need to come up with innovative teaching strategies that will ensure an integrative approach to link theory to practice and to link sciences throughout curricula. Support programmes are needed to help students enhance performance in A\&P. The examination schedules should be adjusted so that student nurses have enough time to study, and nurse educators should engage students in active learning.

Afr J Health Professions Educ 2020;12(3):140-143. https://doi.org/10.7196/AJHPE.2020.v12i3.1357

Professional nurse training in South Africa (SA) takes place within public nursing colleges, which are spread over the nine provinces. There are 14 such public nursing colleges in SA, with 34 sub-campuses. Professional nurse training is offered in terms of regulation R425 of the Nursing Act No. 50 of 1978, leading to registration as a nurse (general, psychiatry and community) or midwife. Anatomy and physiology (A\&P) is a core subject taught in the first year of training. ${ }^{[1]}$ The expectation is that on completion of education and training, students should have good observational, analysis and problem-solving skills, since modern nursing requires awareness of interactions between anatomical and physiological systems in pathological processes..$^{[2]}$

A background in $\mathrm{A} \& \mathrm{P}$ for the 4-year comprehensive basic nursing course is part of strict entry requirements for nursing students. Life sciences entail basic terminology that is used in human anatomy and physiology, and therefore form part of the admission requirements for the 4-year comprehensive basic nursing course. Without passes in life sciences, nursing colleges in SA do not admit applicants, regardless of their grade 12 score, to ensure that all students have at least a foundation in A\&P. ${ }^{[3]}$ The entry requirements for nurse training at the public nursing colleges in SA also include a grade 12 certificate with a minimum score of 25 .

Admission requirements in Australia are similar to those in the colleges under study, as mathematics, science and English are the prerequisite subjects for admission. ${ }^{[4]}$ In Ghana, English, mathematics, science and some age restrictions are basic requirements for admission. Unlike in SA, applicants must be between the ages of 18 and 35 years. This means that applicants under or over the stipulated age categories are excluded from the applications even if they meet the other requirements for admission. ${ }^{[5]}$
However, as reflected in a study conducted by McVicar et al., ${ }^{[2]}$ regardless of strict entry requirements, the performance of student nurses in biological subjects is poor, and this is a global phenomenon. In the UK, first-year nursing students struggle with the biological subjects. A\&P as a biological science subject creates a solid foundation for nursing because it provides a simple approach to describing the body's systems. Understanding of basic medical and surgical conditions is based on the application of knowledge gained in these subjects. ${ }^{[6]}$

\section{Statement of the research problem}

$\mathrm{A} \& \mathrm{P}$ is a core subject in nursing curriculum; it provides necessary knowledge of the structure and function of the human body. The knowledge gained from A\&P provides the foundation for all nursing subjects: for instance, a student cannot learn how to assist a mother during birth without knowledge of the anatomy of the pelvis. The biological sciences entail human $\mathrm{A} \& \mathrm{P}$, and this is a core subject in nurse training. In Australia, students who opted for nursing as a career but did not do natural or life sciences in secondary school performed poorly in A\&P ${ }^{[7]}$ Analysis of results at the college campuses under study in A\&P from 2014 to 2017 indicated that the performance of student nurses in A\&P fluctuated. The pass rates during the period between 2014 and 2017 fluctuated between 54\% and 70\%.

The researchers wanted to identify the factors contributing to the unsustainable performance of student nurses in A\&P, in order to develop measures to ensure that performance improves to close to $100 \%$, as envisioned by the college, and is sustained at that level. At present, despite having a secondary school background in A\&P, students struggle with the subject. ${ }^{[8]}$

The implications of this problem for students are that the students will not be able to master nursing and midwifery as subjects, since A\&P is 
essential to understanding the physiology and pathophysiology of a patient's condition, and the related treatment. They will not be able to provide safe nursing care without success in this module (for example, the names and locations of injection sites are covered in the module). To the best of our knowledge, there is currently no literature in SA on factors contributing to the failure of student nurses in A\&P. Therefore the present article aims to describe the factors contributing toward inconsistent and fluctuating performance among student nurses in A\&P.

\section{Methods}

A quantitative, descriptive research design was used in the study to explain and describe factors contributing to the failure of students in A\&P.

The system of education and training in KwaZulu-Natal Province is unified, meaning that there is one college with 10 campuses spread over the province. The study was conducted in the KwaZulu-Natal College of Nursing, which has 10 nursing campuses. The researchers selected 6 campuses purposively because they contained those second-year student nurses who had completed and passed A\&P. The selected campuses were identified as locations A - F, to maintain anonymity. The inclusion criteria were all second-year student nurses on the selected campuses. First-year student nurses were excluded from the study because they were still studying A\&P, and third- and fourth-years were excluded because some campuses did not include such levels. There were 170 second-year student nurses who met the inclusion criteria. Census sampling was used to select the respondents. Student nurses who met the inclusion criteria but did not consent to participate in the study were excluded, thus voluntary participation in the study was ensured. A sample of 114 second-year student nurses was selected and enrolled in the study. The number of respondents from each of the campuses were: campus A, 21 respondents; campus B, 10; campus C, 24; campus D, 20; campus E, 23; and campus F, 16. The respondents who were selected received questionnaires and consent forms as part of the data collection process.

The self-administered structured questionnaire was used to collect data. The questionnaire was developed following a review of the literature. The questionnaire consisted of four sections. In section 1, respondents' demographic information was gathered; section 2 covered respondents academic performance; section 3 examined respondents' attitudes towards $\mathrm{A} \& \mathrm{P}$; and section 4 examined their general perceptions of A\&P, comprising 18 items, from simple responses to rating scales to graded 5-point Likertscale options with 'strongly agree,' 'agree,' 'neutral', 'disagree' or 'strongly disagree' as optional answers to provided statements.

A pre-test was conducted with five respondents, and thereafter, data collection started on 11 April 2018, continuing until 4 May 2018. The process of data collection took place on the six nursing campuses under study. It took place during respondents' lunch time, during a free period or after school. This was to prevent disturbance during teaching and learning. On arrival at each campus, respondents were gathered in one large classroom. The purpose of the study was fully explained to the respondents by the researchers, and they were given consent forms to sign to indicate their voluntary participation. Completion of the questionnaire was scheduled to take 20 - 30 minutes, although some questionnaires were answered in 10 - 15 minutes. Two sealed boxes, one for consent forms and the other one for questionnaires, were provided to the respondents, so that the signed consent forms could not be linked to the questionnaires, to ensure anonymity.

\section{Data analysis}

The completed questionnaires were collected, and all items were coded appropriately and entered into an Excel spreadsheet (Microsoft, USA). The items were then cross-checked for accuracy. Coded data were transferred to SPSS (IBM Corp., USA) version 24. Demographic data were presented in frequencies and percentages. A reliability test was conducted to statistically determine the level to which the selected set of items measured a single latent construct. Cronbach's a coefficient was computed to statistically assess the degree to which similar responses could be obtained from participants should the same set of questions be asked several times under similar settings to the same group of respondents.

\section{Data management}

A password-protected laptop was used to store all data that were electronically captured. All data in the form of hard copies were stored in a researcher's locked cabinet.

\section{Ethical consideration}

Ethical clearance to conduct the study was obtained from Health Studies Research and Ethics Committee of the University of SA (ref. no. HSHDC/786/2017) and from the National Health Research Database Board (ref. no. KZ_201803_012) of SA. Permission was granted by the principal of the KwaZulu-Natal College of Nursing and also by the principals of the six campuses under study.

\section{Results}

The respondents' demographic profiles showed that: $70 \%(n=80)$ were females; $46 \%(n=53)$ were aged $20-24$ years old and $27 \%(n=31)$ were 25 - 29 years old; $74 \%(n=84)$ were black African and 19\% $(n=22)$ were Indian; and 58\% ( $n=66)$ had completed matriculation (grade 12) after 2008 and $42 \%(n=48)$ completed before 2008. Regarding the schools attended in matriculation (grade 12$), 40 \%(n=46)$ had attended rural schools, $30 \%$ $(n=34)$ suburban schools and 29\% $(n=33)$ township schools (Table 1).

A structural equation model of overall academic performance v. general perceptions showed that only ' 2 hours for the subject examination' exhibited a positive effect on students' performance in A\&P, although statistically, the 2-hour examination had an insignificant effect on students' overall academic performance $(z$-statistic $=1.13 ; p>0.05)$. Although statistically insignificant, all the remaining items were generally perceived to contribute to high failure rates of student nurses in A\&P. Cronbach's a coefficient value $(\alpha=0.700)$ for the finally selected 18 items satisfied the minimum acceptable threshold of 0.700 scale reliability score. The result therefore reveals that items measured a single-dimensional latent construct (Table 2).

\section{Discussion}

The present study determined the factors that contributed to student failure in A\&P, which were: poor teaching strategies; lack of after-class sessions; shorter study period for examinations; and a language barrier. These factors are in line with results from previous studies.

The majority of respondents (43\%) reported that poor teaching strategies of nurse educators were viewed as not being effective in producing good results in A\&P. According to Pinehas et al., ${ }^{[8]}$ in a study conducted in Oshana, Namibia, participants found that poor teaching strategies, poor student-teacher relationships, and communication 
barriers affect academic performance. In a study conducted in the Eastern Cape Province, SA, Tom et al. ${ }^{[9]}$ suggested that nurse educators should fully assist students as part of their educational strategy to help students to understand A\&P. This shows that a good relationship between the educator and students improves student learning outcomes.

The majority of respondents (39.5\%) reported that lack of after-class sessions for those students who did not understand the content contributed to failure. This is similar to the study conducted by Tom et al. ${ }^{\left[{ }^{[j]}\right.}$ which found that students' performance improved when students participated in after-class sessions on academic concepts and general academic and writing skills, and were provided with feedback on assignments. In their study, Tshotsho et al.$^{[10]}$ reported that students gave positive feedback, and described individual class sessions as one of the most useful aspects of the programme. Learning centres that teach students who speak English as a second language (ESL) skills such as grammar, vocabulary and pronunciation have been found to be useful. In their study, Pinehas et al. ${ }^{[8]}$

\begin{tabular}{ll}
\multicolumn{2}{l}{ Table 1. Respondents' demographic profile $(\mathbf{N}=114)$} \\
\hline Characteristic & $\boldsymbol{n}(\%)$ \\
\hline Gender & $34(30)$ \\
Male & $80(70)$ \\
Female & \\
Race & $2(2)$ \\
White & $22(19)$ \\
Indian & $6(5)$ \\
Coloured & $84(74)$ \\
Black African & \\
Age, years & $10(9)$ \\
$15-19$ & $53(46)$ \\
$20-24$ & $31(27)$ \\
$25-29$ & $17(15)$ \\
$30-34$ & $3(3)$ \\
$\geq 35$ & \\
Period matric completed & $48(42)$ \\
Before or during 2008 & $66(58)$ \\
After 2008 & \\
School type attended during matric (grade 12) & $46(40)$ \\
Rural & $33(29)$ \\
Township & $34(30)$ \\
Suburban & $1(1)$ \\
Finishing/bridging school & \\
&
\end{tabular}

found that students, especially those considered slow learners, needed more support from their nurse educators to understand what they had been taught.

Shorter study periods before examination were viewed by the majority of respondents in the present study (44.7\%) as a contributory factor to failure. Similarly, Alos et al.$^{[5]}$ reported that among other factors, constrained study time and limited time in examinations contributed to student failure. Alos et al. ${ }^{[5]}$ further showed that demographic and cognitive factors had different effects on student performance in different disciplines. The study also showed that five main factors contributed to student failure, namely personal conditions, study habits, shorter study and examination times, shorter breaks and home aspects, such as the language commonly used. The system of limited study days, combined with a short, overloaded exam schedule negatively impacted student performance. Pinehas et al.$^{[8]}$ revealed that nursing students reported that the examination schedule impacted their performance badly, especially if there was a short break during the examination and one or more modules were written in a day or in a row.

Additionally, many respondents (48\%) reported that the language barrier contributed to failure of student nurses in A\&P. Students are not taught in their vernacular, and all text books are written in the English language. According to Langtree et al.. ${ }^{[1]]}$ ESL students have difficulties with the English language in the first semester of study, which affects the study of new and complex terms, which in turn negatively affects first-year nursing students and leads to high failure rates. ${ }^{[1]}$ Students' home languages therefore have an influence on their performance at first-year level. An evaluation of a blended learning approach in an A\&P module for nursing students revealed that participants encountered difficulties in using new and complex terms and concepts. ${ }^{[12]}$ For this reason, students reported that $\mathrm{A} \& \mathrm{P}$ was the most difficult subject in nursing programmes. On the contrary, however, Manson ${ }^{[13]}$ reported that participants with higher matric scores in isiZulu performed well academically in several nursing subjects compared with speakers of English or other languages.

\section{Recommendations}

The recommendations below are drawn from comments by the respondents, and from the literature, and may be utilised by nurse educators to facilitate effective teaching of A\&P:

- Use of the following should be considered: presentations by peers (peer group teaching), poems, songs, storytelling and visuals; a skills laboratory for visualisation of models; anatomy quizzes and puzzles.

- Examination schedules should be adjusted so that student nurses have enough time to study.

Table 2. Structural equation model of overall academic performance v. general perceptions items $(N=114)^{*}$

\begin{tabular}{llllll}
\hline Structural overall academic performance & Coefficient & Robust SE & $z$ & p $>$ IzI & 95\% CI \\
\hline 2 hours for the subject examination & 0.096 & 0.085 & 1.13 & 0.257 & $-0.070-0.264$ \\
Teaching strategies & -0.062 & 0.108 & -0.58 & 0.564 & $-0.276-0.150$ \\
1-day study in between exams & -0.068 & 0.077 & -0.89 & 0.371 & $-0.219-0.082$ \\
Home language & -0.005 & 0.081 & -0.07 & 0.942 & $-0.165-0.153$ \\
No after-class sessions provided & 0.020 & 0.085 & -0.24 & 0.808 & $-0.187-0.146$ \\
Construct & 2.347 & 0.459 & 5.11 & 0.000 & $1.446-3.248$ \\
Overall academic performance & 0.818 & 0.084 & - & - & $0.668-1.000$ \\
SE = standard error; CI = confidence interval. & & & & &
\end{tabular}


- Support programmes are needed to enhance performance in A\&P.

- Future research should be conducted on factors contributing to the failure of student nurses in A\&P; studies should include other provinces and universities.

\section{Study limitations}

The present research was conducted only at those six campuses of a public nursing college that had second-year nursing students. A sample size of 114 student nurses was obtained. Consequently, the findings cannot be generalised to other nursing colleges, nursing education institutions or provinces. The questionnaire was closeended and did not allow respondents to state their views.

\section{Conclusion}

The results showed that home language significantly affected students' overall academic performance in A\&P at a public nursing college. Conversely, students' overall academic performance in $\mathrm{A} \& \mathrm{P}$ was constrained by: poor teaching strategies; lack of after-class sessions; shorter study period for examinations; and the language barrier.

Declaration. This article was based on a study done by XLM in fulfilment of his MA in nursing science.

Acknowledgements. The authors are grateful to all their co-workers for their support and guidance during the writing of this article.

Author contributions. XLM: identified the research topic, conceptualised the study design, formulated the research aim and objectives, performed the collection and interpretation of data and drafted a version of the article. TEM: supervised the study and assisted with writing of the article. Both authors approved the final version of the manuscript.
Funding. None.

Conflicts of interest. None.

1. Montayre J, Sparks T. Important yet unnecessary: Nursing students' perceptions of anatomy and physiology laboratory sessions. Teach Learn Nurs 2017:12(3):216-219, https://doi.org/10.1016/j.teln.2017.03.009

2. McVicar A, Andrew S, Kemble R. The bioscience problem for nursing students: An integrative review of published evaluations of year 1 bioscience, and proposed directions for curriculum development. Nurs Educ Today 2015:35(3):500-509. https://doi.org/10.1016/j.nedt.2014.11.003

3. Department of Health Studies, KwaZulu-Natal College of Nursing. Curriculum: Diploma in Nursing (General, Community and Psychiatry) and Midwifery. Pietermaritzburg: Government Printer, 2010b.

4. Ralph N, Rogers C. Entry requirements in nursing: Results from a national survey of nurse academics on entry requirements in Australian bachelor of nursing programs. https://doi.org/10.1016/. COLEGN.2018.06.005

5. Alos SB, Caranto AL, David JJT. Factors affecting the academic performance of the student nurses of BSU. Intern Nurs Sci 2015;5(2):60-65. https://doi.org/10.5923/j.nursing.20150502.04

6. Ross AW, Wilson AG. Anatomy and physiology in health and illness. 12th edition. Edinburgh: Elsevier, 2015

7. Cox JL, Crane CJ. Shifting the focus: Increasing engagement and improving performance of nursing students in bioscience subjects using face-to-face workshops to reduce anxiety. Inter J Innov Sci Math Educ 2014;22(7):11-22.

8. Pinehas LN, Mulenga E, Amadhila J. Factors that hinder the academic performance of the nursing students who registered as first year in 2010 at the University of Namibia (UNAM), Oshakati Campus in Oshana, Namibia. J Nurs Educ Prac 2017;7(8):63-71. https://doi.org/10.5430/jnep.v7n8p63

9. Tom F, Coetzee I, Heyns T. Factors influencing academic performance in biological sciences among students in nursing education institution in the Eastern Cape Province of South Africa: An appreciative inquiry approach. Afri J Phy ed

10. Tshotsho B, Mumbembe L, Cekiso M. Language challenges facing students from the Democratic Republic of Tshotsho B, Mumbembe L, Cekiso M. Language challenges facing students from the Democratic Republic of
Congo in a university in South Africa. Inter J Educ Sci 2015;8(3):597-604. https://doi.org/10.1080/09751122.2 Congo in a university in South Africa. Inter J Educ Sci 2015;8(3):597-604. https://doi.org/10.1080/09751122.

11. Langtree EM, Razak A, Haffejee F. The effect of speaking English as a second language on the study of anatomy and physiology in the nursing programme. S Afr J Higher Educ 2018;32(1):129-139. https://doi.org/10.20853/32 $1-793$

12. White S, Sykes A. Evaluation of a blended learning approach used in an Anatomy and Physiology module for pre-registration health care students. Paper presented at the Fourth International Conference on Mobile, Hybrid, and On-line Learning held on January 30, 2012 to February 4, 2012 in Valencia. London: University of Huddersfield, 2012.

13. Manson TA. The relationship between matriculation English results and academic performance in nursing students at the KwaZulu-Natal College of Nursing. Durban: Durban University of Technology, 2014.

Accepted 19 June 2020 